\title{
Garnet Abundance in the Tibes Skarn, Puerto Rico: Implications for Unraveling Ore Genesis and Mineralization Processes
}

\author{
DAVID A. GIOVANNETTI-NAZARIO ${ }^{1}$, THOMAS R. \\ HUDGINS $^{1}$, LAURA D. BILENKER ${ }^{2}$ AND MARISA \\ BAREFOOT $^{2}$ \\ ${ }^{1}$ University of Puerto Rico, Mayaguez \\ ${ }^{2}$ Auburn University \\ Presenting Author: david.giovannetti@upr.edu
}

Puerto Rico hosts three iron skarn deposits that have been historically mined for iron ore. Despite this early exploitation, they have remained understudied due to restrictive local mining laws. Of these deposits, the Tibes Skarn is located along the Portugués River in the southern region of the island, providing a continuous exposure of the deposit and the igneous body likely responsible for its formation. The current outcrop provides a perfect natural laboratory to investigate the processes involved in its genesis and evolution. Preliminary mapping has distinguished three distinct zones in the area: a garnet + epidote + actinolite zone, a zone of massive magnetite, and a hornfels zone. The massive magnetite present in the area are found as large tabular bodies which are structurally related to an extensive fault zone. While preliminary geochemical analyses of these magnetite are inconsistent with skarn formation models, the wide assortment of garnet throughout may serve as an essential tool to further elucidate the Tibes Skarn's origin. Field observations show that garnet of varying size and morphology is present throughout Tibes as large veins and clusters. These minerals also typically co-exist with massive, recrystallized calcite, hydrothermal quartz, massive magnetite, and other tabular features akin to dikes. A significant feature observed petrographically is a garnet crystal with a birefringent rim and an isotropic core, indicative of multiple events or generations of garnet mineralization. Preliminary geochemical analysis shows garnet composition to be that of grandite, a grossular-andradite solid solution, which are a common occurrence in iron skarns and other ore deposits. Hence, the abundance of garnet can provide insight into: a) the composition and dynamics of fluids responsible for the skarn and its associated ores, b) the timing of mineralization events, and c) better constraining the classification of the Tibes ore deposit. 